\title{
Design of Controlling Supported Sustainability of Manufacturing Enterprises
}

\author{
Eryk Głodziński \\ Warsaw University of Technology, Faculty of Production Engineering, Warsaw, Poland \\ e.glodzinski@wip.pw.edu.pl
}

\begin{abstract}
In the paper the controlling as a management concept supporting sustainability of enterprises was characterised. Controlling is treated as a very important element of managerial accounting system in manufacturing companies. In the first part of the paper the company sustainability was presented. Next the stages of controlling design were characterised. In the third part of the paper the controlling model was shown. Finally, various controlling supporting instruments enabling the balanced growth of manufacturing enterprises were listed. The relationships between them were presented.
\end{abstract}

Keywords: controlling, design, modelling, management tools.

\section{Introduction}

On global economic market the enterprises should operate basing on the criteria of efficiency, effectiveness and social responsibility. These criteria are the basic assessment factors in decision-taking process of companies applied strategy of balanced growth. In such case, the weight of each criterion is depended on many determinants e.g. economic situation of the company and on the market, competitor's position of company or expectations of society and other stakeholders. The decision-taking process is the major element of management process and should be supported by creating proper information using complementary various management tools. These tools can be divided into three groups: concepts, methods and techniques.

The paper presents the results of research connected with design of controlling as a concept, which supports production management. The research is based on the analysis of selected, existing controlling systems in international companies present on the European market and the application proposal of universal model of controlling design created by S. Marciniak [5] to the manufacturing companies. The main thesis of the paper is the assumption, that controlling will support sustainability of manufacturing enterprises if the design process follows the right methodics. A proposal of the proper methodics will be presented in the paper. The article does not take into consideration the issue of sustainability of products, but analyses sustainability of company by developing the products. 


\section{Sustainability of the Company with Controlling}

Controlling in paper's meaning should deliver proper information for decision-taking process and is associated with the early-warning-system against threats. The controlling connects many planning and control methods/techniques. One of the most important stage of designing the controlling is to choose and integrate these tools in one system targeting on the strategic goals of company.

Sustainability means being able to operate on the market, overcoming the problems which could threaten the normal existence of enterprise, ensuring the company development in long-term period. Regarding the manufacturing enterprise, sustainability in current market conditions can be associated with:

- assembling of goods avoiding the production interruptions (like accidents at work place, equipment failures, delays in material delivery etc.),

- reducing waste (by assembling the goods according to the technological documentation, ensuring the quality of services and the supplied materials, maintenance management etc.),

- recycling the waste when it occurs (re-use the material in other technological processes, store the waste in an environment-friendly way),

- developing all company: units, function and processes, especially manufacturing processes and other supporting processes like R\&D, supplying etc.

It will be possible, if the company is able to control its activity, especially in the above mentioned tasks. Control of activity has to be preceded by planning. Both processes should be integrated in the company as one controlling system. In practice, the integration means collaboration of various methods and techniques of management. The issue is to choose the ones which could be used complementary. It is obvious that the system should simultaneously use the results (information) of the above mentioned processes. Aggregation of selected management methods and techniques can proceed by controlling concept. Its main principles are: establishing measurable goals, continuous analysis of target and current data, predicting the future, providing cost account in accountability centres, applying of feedback loops. It is important, that controlling system should not use especially the tools, which can provide contradictory results or cost of providing data is too high in comparison to their decision value.

In the assembled sector of economy planning and control processes are based mainly on the measurable (quantitative) indicators e.g.: degree of the use of production capacity, amount of sales revenue, amount of production costs, number of finished goods in comparing to the waste. However, ensuring the sustainability of company with controlling requires including not only quantitative assessment but qualitative as well. The main issue is applying and aggregating both results in one system. The solution of such a problem could be a design of special assessment system unique for the company or basing on existing tools e.g. created in 1996 by R.Kaplan and D.Norton the Balance Scorecard [3], which divides the goals of company into four perspectives: financial, internal business process, learning and growth, customer. The above mentioned management tool translates a business unit's strategy into tangible objectives and measures. One of the major problem of design 
process is the measure the factors which are not quantitative. These issues have not been solved satisfactorily by researchers and practicans till today. Nevertheless Balance Scorecard is currently very popular in business and in research works as well. Regarding the works of research, especially Nobel prize winners in economics ( $\mathrm{J}$. Stiglitz [7] and P. Krugman [4]) and after the start of worldwide crisis in 2008 the approach to assessment of company activity (object of planning and control) should be partly revised. Now the most important goals of company could be divided into three groups: achieving satisfactory financial result (economic indicators), doing the business regarding the social aspects (connected with employee and society -social indicators) and protecting the natural environment (environment-friendly indicators). Selected groups of criteria are a part of the economics balanced growth theory. The theory is especially important for middle and big enterprises which want to operate and develop on the market in next several years. In such case they have to measure not only financial indicators but non-financial ones as well. Small companies characterise by different range of problems. Vital operating factor for most of them is financial result and sustainability is associated mainly with low-cost operating. Even thought keeping the sustainability in developing economy requires having good social relationship with the society. The relationship is created especially by brand image key customer care, good supplier network, environmental-friendly behaviours. The last mentioned factor is built minimizing the number of waste and emissions.

\section{Conditions and Stages of Controlling Design}

Before the process of controlling creation starts, the conditions of designing, modelling, implementation, and using the system in specific application area should be researched. Manufacturing enterprises differ from service companies mainly by:

- tangibility of products (the tangibility level is much higher),

- storage possibility,

- level and degree of contact between producers and consumers (the contact between the production force and clients is occasional),

- length of response time between the order and execution (depends on the length of production processes),

- labour intensity and the use of machinery (predominately the high level of automation),

- frequency of replacing the machinery (very often, which influence high level of amortization/depreciation).

In the controlling design process, the efficiency and effectiveness of company operating should have the some priority. It has to be taken into consideration that price and next the quality of products are for customer most often more important than the manufacturing technology or place. The controlling's measurement system should include the formulas, which analyse and asses these indicators. From the perspective of manufacturing enterprise is vital relationship between sales figures, brand image, product launch or product placement. These indicators are hardly measurable (it is necessary to use indirect measures). Regarding the above mentioned issues the controlling design process can be executed in following stages: 
1. Analysing business processes regarding the economic, social and environmentfriendly goals.

2. Analysing the existing frameworks of enterprise.

3. Choosing the areas supported by controlling and sequence of implementation.

4. Designing new or redesigning business processes regarding the concepts management by processes and targets.

5. Presenting controlling system in the form of model to enable better understanding.

6. Redesigning frameworks.

7. Integration management functions esp. planning and control of production in one system.

8. Designing measurement system of enterprise goals basing on universal model of controlling design [5].

9. Updating the model to the more developed form.

10. Designing motivation system based on responsibility account and results achieved by company staff.

11. Completing the model before test phase.

12. Testing the model.

13. Updating the model after the completed test phase.

The designing process in management generally bases on the principals, which were created for engineering science and economics. They could be adopted in major points in management science. Technical rules of designing the controlling are as follows:

1. Designing should encompass all the structural elements included in the system.

2. Designing should be implemented in two layers:

a) globally, where all organizational units are the units subject to the design,

b) structurally, where we design the internal structure of organizational units.

3. Connections should be designed (dependences, coupling) between units of the structure without specifying the mode of implementation of the connection; It is necessary to verify the connections (so-called static verification of relationship between the elements of the system).

4. The time and the sequences of execution of the connections (dependences, coupling) need to be specified.

5. Verification of carefully time identified connections (so-called dynamic verification of te relationship) should be executed.

6. The implementation procedures should be designed in accordance with the system that allows the transformation of the dynamic model of the system into real specificity of the company; It is necessary to complete the implementation procedures with analysis and model management methods.

7. After the procedures have been designed it is necessary to check again the regularity of information flow and decision-taking (simulation); It is necessary to design technical tools supporting the functioning (operating) of the system, mainly of IT nature,

8. The test of practical functioning of the designed system is performed (verification) [6].

Controlling department, situated as a unit supporting top management in access to information, is responsible for protecting and developing the controlling philosophy (methodology consistent and common for each unit of company). Other tasks include: 
developing the controlling tools, data aggregation, data benchmarking, reporting, decision recommending. These tasks arise from controlling functions:

- planning and evaluating measured areas,

- planning targets figures,

- monitoring business processes,

- collecting data describing operational activity of company,

- analysing data from data base,

- assessing information,

- creating financial and managerial reports,

- delivering reports to the right people.

Regarding the above mentioned processes and functions, controlling should be focused on following areas (in sequence of applying):

1. Finance (major issues: cost and revenue accounting, analysing incoming and outgoing payments, measuring assets and equity, analysing liabilities etc.).

2. Manufacturing (major issues: providing production capacity, measuring quantity of outputs -especially prime products, checking quality of goods and subcontractor services, checking margins, analysing time schedule etc.).

3. Sale and after sale services (major issues: targeting margins and production capacity, measuring and analysing satisfaction of clients, pointing out key clients etc.).

4. Procurement (major issues: analysing efficiency of deliveries, checking quality of materials, measuring and analysing satisfaction from cooperation with suppliers etc.).

5. Storage (major issues: measuring and analysing quantity of inventories).

6. Maintenance (major issues: checking natural depreciation of machinery, checking productivity of machinery, measuring and analysing satisfaction from cooperation with machinery producers and services etc.).

7. Environment protection (major issues: checking quantity of emissions and nonrecycled waste, measuring and analysing impact of company operation on natural environment and economic development etc.).

8. Human resources (major issues: measuring achievement of the person's goals, analysing work performance, targeting gained experience, knowledge and skills etc.).

The above mentioned sequence bases on the criteria: the specifics of the company (due to assembling goods), value of benefits connected with implementation (additional profits or reduction resource consumptions) and opportunity to use other management concept (when it is not necessary to apply controlling in the selected area). Implementation of controlling in selected areas should accompany application of the company controlling. Its main targets are assessing and raising the stakeholder value, protecting the company against threats (in perspectives of economy, society and environment) and planning and controlling activity on the highest level (most aggregated) of the company.

In designing process the vertical integration of planning and control is one of the most difficult issues. In practice it means using the same measures in both processes, which gives opportunity for benchmarking and variance (deviation) analysis. The second form of integration is horizontal approach. It means using measurement 
system which enables data aggregation. It is possible when all financial and nonfinancial indicators can be presented in monetary unit. A valuation of non-financial indicators, like environmental-friendly behaviours, is quite a difficult problem to overcome. It is a big challenge for somebody who designs the controlling.

\section{$4 \quad$ Model of Controlling System}

To ensure both forms of integration and fulfil the established targets all designed elements of controlling should be evaluated before the real application. One of the best methods to achieve it is creating the conceptual model of controlling. It is a theoretical framework that can be used to present in a simple way all elements of controlling and relationship between them.

The controlling model consists at least of:

1. Various structural elements (objects like company and product strategy, data base or using management tools and subjects like key users and end users of controlling system and receivers the information).

2. Relationship between elements constituting this model (in form of mathematical formulas or form presented various data described state of the research subject),

3 . Controlling process description (guidelines outlining methodology of planning and controlling).

For better transparency the controlling model should be presented with graph techniques e.g. used in IT the methods of block scheme (fig.1).

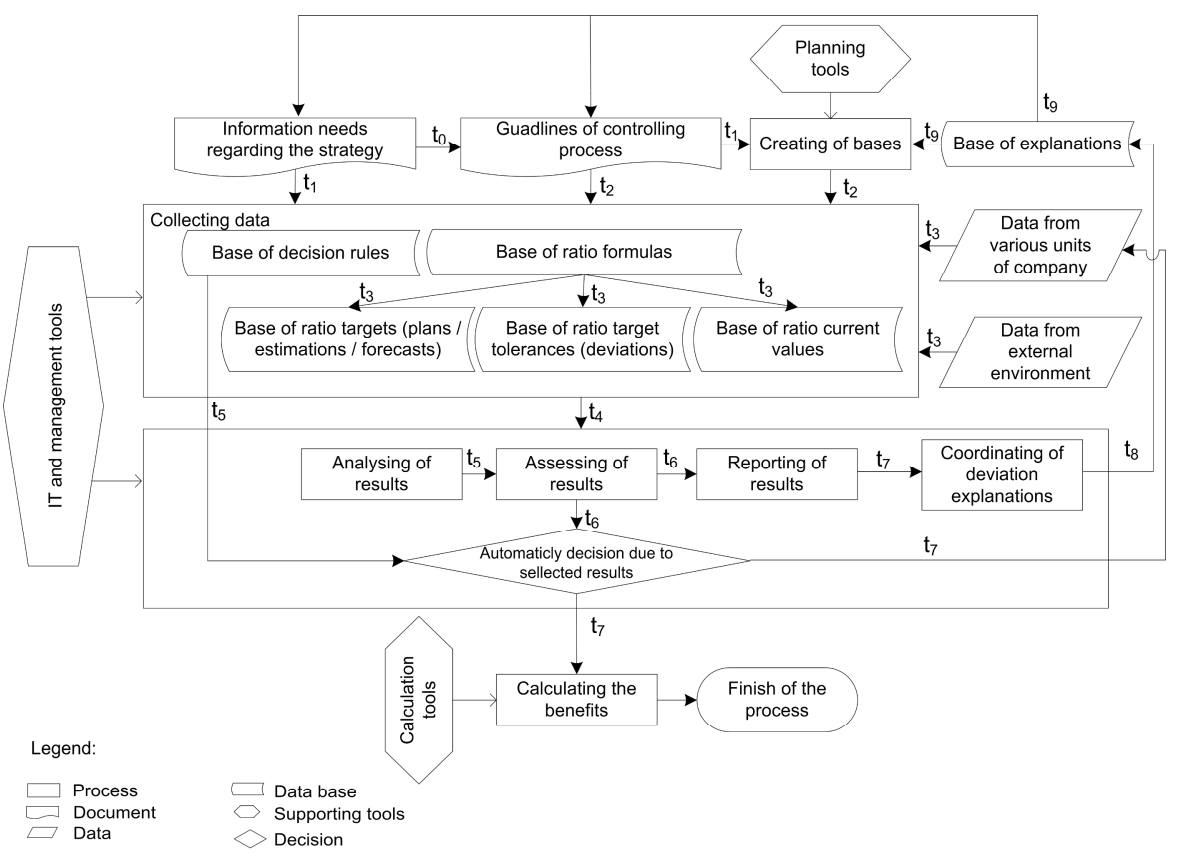

Fig. 1. Model of controlling system (Source: own study) 
The elements of controlling model are as follows:

- strategy of enterprise based on targets (e.g.: margin, quantity, quality, market position),

- set of sources to obtain external information about resources, technologies, demand, supply etc.,

- set of methods/techniques to obtain external data and information,

- set of sources to obtain internal information about resources, technologies, organisation aspects of the company etc.,

- set of methods/techniques to obtain internal data and information,

- set of methods/techniques for calculation of target data,

- set of methods/techniques for measuring amount of current data,

- set of methods/techniques for analysing, assessing and reporting,

- set of methods/techniques for calculation the benefits in motivation system,

- data bases of: measurements (formulas used for measuring), target indicators (target values for benchmarking), target tolerances (limitations of targets for benchmarking), up-to-date dates (current data presenting actual statement), decision-taking rules in approach to assessing process, explanations (remarks to exceeded limitations).

All the above mentioned elements should be obtained during the designing process of controlling. One of the most important stages by designing process is selecting management tools (methods/techniques) supporting the system.

\section{$5 \quad$ Selected Tools Applied in Controlling}

The management tools can be described as intangible objects which help to achieve management goals of the company. The literature describes many examples of methods and techniques used by manufacturing companies [2]. Not all of them could be applied in controlling system. It should be focused especially on:

- quantitative presenting of operation activity (core processes) of the enterprise (in approach to: materials, goods in progress, finishing goods, storage goods, goods sold etc.),

- continuous analysis of the company results on operational (especially manufacturing and investment activity) and financial (especially working capital analysis) levels,

- valuating of qualitative aspects of company activity regarding the balance growth theory (especially satisfaction from using goods by the clients),

- the use of variance (deviation) analysis as a leading approach to assessment of the business results,

- providing the feedback loops of information during the manufacturing process,

- connecting various tools of management in one system.

Selection of methods/techniques should take into consideration their cooperation (plan data can be measured and collected next analysed and aggregated, finally evaluated on various level of aggregation, and reported). The tools applied in 
controlling can be presented regarding the functions of controlling and their usefulness for achieving various goals (fig. 2). These goals, as mentioned previously, results from balance growth development. Such approach requires doing analysis regarding effectiveness and efficiency in economic, social and environmental-friendly areas.

Regarding the controlling philosophy, it is important to use the result from assessment process to improve the sustainability of company. Company staff should be enough motivated to follow the strategy and resulting from it activities. From operational point of view it means, that the above mentioned behaviour is characterised mainly by proper use of management tools, right activity in right time, and continuous improvement of management system. It results in applying the

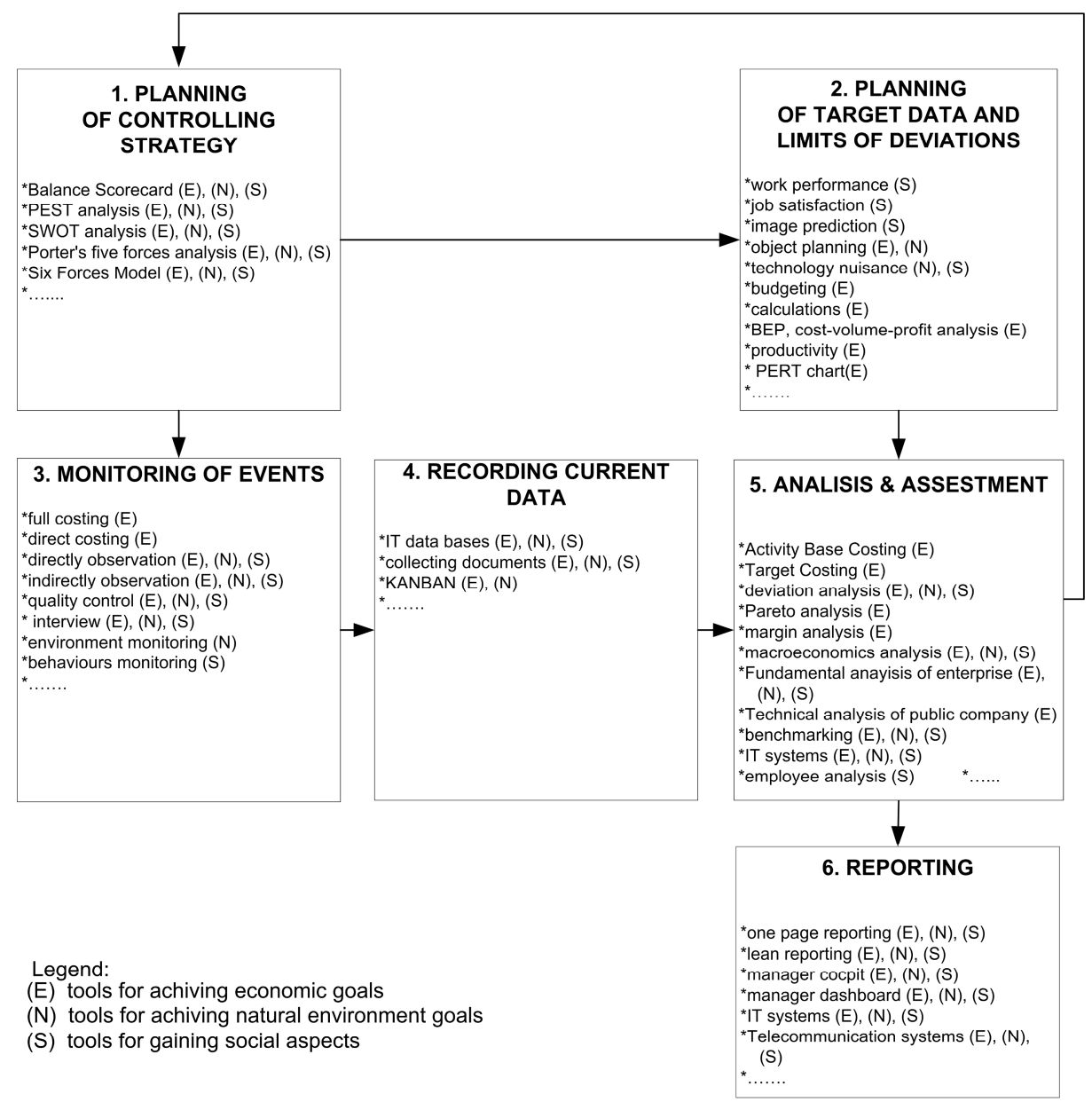

Fig. 2. Selected management tools supported controlling in manufacturing enterprise (Source: own study) 
motivation system as an element of controlling. The bonuses (benefits for employee calculated from controlling system) have in this case a financial form. If controlling informs about the level of indicators describing company activity (economic, social and environmental aspects), the motivation system will base on measured data. It helps to avoid increasing the additional costs. Bonus system can base on:

- financial result of company,

- financial results of company units,

- financial results of projects/orders etc.,

- change of share value (by public companies),

- level of meeting the budget,

- level of employee absence,

- level of employee innovation,

- share in establishing targets.

In controlling the motivation system should be easy to understand by employees. The formula of bonus calculation should not change during the assessment period of time.

\section{Conclusions}

Sustainability of enterprise can be assessed using the controlling as a "going concern" principle, which is known from financial accounting. This approach means treating controlling as an early warning system, which consists of proper measurements and implemented procedures (decision rules) in action needed situations.

Without controlling concept the management tools generally are used separately. In this case achieving established goals of enterprise is at risk, because each unit of company tries to maximize its own targets. To avoid such situations controlling principles require cooperation and joint use of all enterprise resources. The success of controlling, in meaning of establishing the company sustainability, depends on many factors. Two of them, namely the applied design methodics and supporting management tools have been analysed in the paper. The major assessment areas like: finance, manufacturing, sale, after sale services and procurement have been presented. Summarising, existing and proven (tested) tolls supporting controlling in such system should be used. All elements of the system and the relationship between them have to be expressed in form of conceptual model which helps in its understanding, evaluation and application. For company management is important to link controlling system with motivation system because it results with better efficiency and effectiveness.

Acknowledgements. This work partly presents the results of research from a project number N N115 294338, which has been financed by the Polish Ministry of Science and Higher Education in years 2010-2013. The author wants to acknowledge other members of the project from Warsaw University of Technology for their collaboration. 


\section{References}

1. Anupindi, R., et al.: Managing Business Process Flows. Principles of Operations Management, p. 276. Pearson Education, New Jersey (2006)

2. Harrison, D.K., Petty, D.J.: Systems for Planning and Control in Manufacturing. Systems and management for competitive manufacture. Newnes Publishing House (2002)

3. Kaplan, R., Norton, D.: Using the Balance Scorecard as a Strategic Management System. Harvard Business Review (January-February 1996)

4. Krugman, P., Wells, R.: Economics. Worth Publishers (2009)

5. Marciniak, S.: Controlling. Filozofia, projektowanie, pp. 101-110. Difin Publishing House, Warsaw (2008)

6. Marciniak, S.: Design and modeling of the controlling in manufacturing enterprise. In: Dilemmas of the Contemporary Economy Facing Global Changes, pp. 219-228. Cracow University of Economics, Cracow (2012)

7. Stiglitz, J.: Globalization and Its Discontents. W.W. Norton \& Company, New York (2002) 